\title{
Using Simulation and Virtual Practice in Midwifery and Nursing Education: Experiencing Self-Body-World "Differently"
}

\author{
Susan James, Laurentian University, School of Midwifery \\ Email: sjames@laurentian.ca \\ Brenda Cameron, University of Alberta, Faculty of Nursing \\ Email: bcameron@ualberta.ca
}

\begin{abstract}
The journey into the world of midwifery or nursing requires the student to attend to the intertwining of self-body-world ${ }^{\mathrm{i}}$ in order to shift their knowledge of self-body-world into a client/patient-centered context.

One of the teaching-learning strategies used to provide safe opportunities is the use of simulations and virtual practices. Rather than learning intimate acts of touching, or life and death decision-making in situations with actual clients/patients, students enter their learning world with rubber torsos, cloth babies, and cyber clinics. The "other" is a simulated other, not a human. How does the student shift from seeing this simulated other as object to a sense of other as subject? In our world of constant use of technology for communication and entertainment, do students shift in and out of a cyber world easily or are they more captured by the simulated experience than with the human world? Has the human world redefined itself where the intertwining of self-body-world blurs the sense of where human body ends and cyber or simulated world begins? What is the place of Bildung when engaged with a cyber other?

As a result of educational challenges, including rising enrolments, limited clinical placement opportunities, and increasing risk management concerns, there has been a proliferation in the use of simulation ${ }^{\mathrm{ii}}$ as a teaching strategy (Fox, Damazo, 2013; Schmitt, Gilbert, Brandt, Weinstein, 2013). This has left us -the authors ${ }^{\text {iii }}$ —wondering about the student experience of simulation. What do they learn? How do they learn? How can this learning be applied in practice?
\end{abstract}

\section{The Midwife's Experienceiv}

I sit on the bed across from the woman, waiting for the baby. My legs are intertwined with the woman's, providing support. I am sitting very close to her; I can feel the strain of her muscles as she pushes, our breathing synchronized. At the height of the next push, I both hear and feel the pop of the taut membrane enclosing the water. I can smell the blood and amniotic fluid that are now running toward me. As the head begins to emerge, the woman and I reach our hands to catch. Woman - baby - midwife as one, as two, as three. Senses heightened touch, smell, taste, vision. From inside to outside. The midwife's world. 
The notion of self-body-world is often the attraction to midwifery (while few would be able to boil it down to these three words). The privilege of following a woman from conception to mothering, witnessing birth, being one of the first to touch the baby as she/he enters the world are all part of the work of midwives. But, how does the midwife "wannabe" become the midwife - where work and self merge and there is a sense of a midwife identity or "I-ness"; where the enjoyment of these acts of care are situated in the woman-to-woman relationship and not as a form of entertainment or enjoyment for the practitioner?

Can the midwife's world be simulated? Can the intimate interlacing of self-body-world be replicated with a few body parts of a mannequin or doll? If not, what parts could be successfully enacted in a simulation and which cannot? And, why would we want to use simulation at all? Harder (2010) in a systematic review of high fidelity simulation found that this activity did seem in twenty-three studies to increase skill acquisition, important to the education of health professionals. The simulation activity to be effective needs to include pre-testing or post-testing activities. But, she also cautioned that there was a lack of consistent evaluation tools pertaining to high fidelity simulation.

As I (Susan) consider the education of the midwife/nurse, I reflect on one meaning of Bildung - one of those philosophical words that defy English translation - as education or formation (Bohlin, 2008). Naturally, in a professional program, there are clearly defined educational goals. Educators want to "form" the student to become a competent and safe practitioner. We are often directed via regulatory standards of the very specific knowledge and skills that must be mastered before the end of a program. But, like the ambiguity of understanding Bildung - how do we articulate in curriculum terms such mastery as the notion of self-body-world in a way where we see the intertwining of professional and client? Intertwining is not just about learning the correct skills to apply; but, rather, forming a midwife who deals with the living mother, baby, and family and there is always a specific form that comes to be during a birth. Living form writes art philosopher Suzanne Langer (1957) is a vital activity in the formation of art where felt life comes to the fore"(p. 48). Living form includes the character of "inviolability and fragility" (Langer, p. 50). Life is contingent as is the birth process and this is well known to the midwife. It has a beginning and an end-often not very predictable. So, how do we take this and put it inside a simulation activity?

Or as Gadamer (1992 cited in Bohlin 2008) writes,

Bildung involves moral self-cultivation - we need opportunities to discover both that there is a question, problem, dilemma and then to develop an approach to it that is not necessarily based in pre-existing cultural norms/values. But what about safety? Reflective practice, transformative learning are all useful approaches - but how does the patient/client fit?

Canadian midwifery programs are structured so that theoretical learning is clustered in the first year and a half. While students will have further theoretical requirements during the next two and a half years, the foundations are taught while students are on campus and not actively involved in clinical practice. Most of our clinical preceptors also expect that the students will be already at a novice level in their clinical skills before they begin their first placements. Hence, the dilemma: on one hand, building a program that takes the best of academia and apprenticeship, but then on the other, running into a chicken-egg situation where the place where we think best practices in 
clinical teaching and learning occur is reluctant to actually introduce the teaching of clinical practice.

Traditionally, many health programs begin teaching with practice on one another. This seems a simple solution; students are humans and the cost to the program is negligible. Practitioners close to retirement of my age likely remember practicing bathing, blood pressure measurements, health history taking, blood sampling, reflex assessments - and for midwives, the speculum exam ${ }^{\mathrm{v}}$ - a veritable rite of passage for the midwifery student. In earlier years, health care professional schools may have set up a clinical practice classroom or lab with the appearance of a healthcare setting - even if it really never resembled the settings in which professionals worked.

Now, students tend to become bored quickly in these situations. Only a few seem to have the imagination to fall into a client or patient role, telling the story of her/his life-world from a health perspective. As I walk from one student "couple” to the next, I often find them chatting rather than carrying out a systematic health history. I reflect: "Ok, do I mind if they chat their way through a health history? Not at all, but this chatter is more often about a boyfriend or the assignment for their pharmacology course or gossip about one of their classmates." I reflect on this practice exercise - while both are clearly assuming their subject self-body-world roles, they are at the same time caught in an object self-body-world. They are very aware of the gaze of the professor and are thinking through the steps of the task at hand. The student-patient/client experiences the touch and questions of the student-midwife while at the same time she is listening as a student-midwife. How long can one transition back and forth between object and subject? If the purpose of the practice exercise is to find out about another while looking at the other's face, a fellow student, must the student in some way make a shift to see the exercise as an object to be done, so the fellow student becomes an object for a time to get the task done? However, they do not really make a shift to seeing the other as object because they try to humanize the situation with chatter, to keep both as subjects.

We have been, perhaps, naïve in our use of this teaching-learning strategy, believing that role-play as a form of simulation can replicate the actual clinical experience. Issues of privacy, culture, touch, and human rights have led many programs to restrict the hands-on learning situations with students practicing on students; recognizing that these acts may give far more access to one's life-world than student colleagues ought to have.

These and other circumstances have led to the proliferation of simulated learning. Perhaps a very effective way of addressing Gadamer's (1992) concerns that when we teach, we do not provide the student with the ability to achieve moral self-cultivation because we present both the "problems" and "solutions." There are right and wrong ways and in many cases, the consequence of not seeing the problem or not choosing the "correct" solution is that lives can be threatened. In simulation, the risk to the "patient" is avoided. The student can face a situation, over and over, determine whether or not there is a problem and explore what might be done when there is a problem to confront. We find ourselves in the learning labs and virtual classrooms facing rubber body parts, computer animated sim-women (Noelle $\complement$, the birthing woman) and virtual case studies complete with avatars.

The question then becomes whether or not the student incorporates the moral responsibility for the real world situations when the other is a non-human object? We cannot hurt, we cannot kill, we do not neglect or injure. 


\section{The Nurse's Experience: A memory from a Teacher's J ournal}

Simulation was added to my fourth year nursing practicum course; not an optional event, but a mandated one. We had been able to purchase the simulation dolls and associated computer mechanisms to simulate some emergency situations. The students had a cardiac event scenario to prepare for that morning. Three to four students at a time entered the simulation/nursing wardroom. The other students were in a back room intently watching these students and action unfold and soon it would be their turn. There was a one-way window on one side of the room and the operator behind the windows suddenly became the voice of the patient, the doctor, the lab technician, and whomever else the students decided to call upon on the telephone in the room. As the first group of students came into the room I played the role of the worried yet obnoxious daughter flitting around interfering in the assessment and management of the patient by the nursing students.

As I got into the role myself really mimicking real life nursing situations I had lived through with family members at the bedside of the very ill, I was merely play-acting. The students who were faced with changing vital signs, and oxygen levels of the patient, with shifting scenes in terms of what the operator was doing with the patient, at first milled around, cited theory to each other. As they did this, I got more animated as a daughter. So there we were flitting around a doll controlled by an operator outside the room watching us as if through Sartre's keyhole all the while choreographing this event. And the awareness of the remaining back room students' gaze on us, which we interpreted as an objectifying gaze, remained very present in all our minds.

But very suddenly and surprisingly to me, the students shifted. They began acting as a team, one assessing, one recording, one reading orders, talking to the patient, calming me down as the daughter, asking me to stay put in a near corner, telling me I could stay if I did not get in the way. In the debriefing the students evoked newer literature saying it was beneficial to family to be present when resuscitating a loved one, literature I knew and was delighted when they activated it.

Later I thought, 'How did they shift so fast like that after the first five minutes of meandering around?' But they did. And somehow they decided to treat the doll like a real person-as the drama within the room grew staged again by the operator outside the room. When I asked them to describe this later at the debriefing, they just said suddenly the four of them started working together. They had been very nervous about the 'watchers' and very anxious about how to perform in front of an audience and were afraid of what the other students might think of how they did. And this was before the operator activated a truly lifethreatening situation on the doll. I thought then that the operator must be very skilled in simulation as well and that being an operator is too a practice just like nursing. The students also told me as the daughter I helped them move into the role as I was acting so differently from Brenda. As well, they saw that they could do something with a real person actor like myself because the doll did not seem 
human at all-its voice not even coming out of its throat. But all this did not matter once the students got working together with what was going on, whether or not we were acting subjects or just responding to stimuli in this scenario. It was all about taking action to work together through what was constantly coming towards them and as they saw what was stretching out in front of them in the progression of the cardiac arrest. In writing my reflections on this event, I realized that what activated them was not the doll and computer at all; it was too difficult to make the leap to seeing this doll as a real person. Rather, the leap they made was to respond to each other and to me in my role.

As I (Brenda) wrote more about this experience with simulation, I thought of Seamon and Zajonc's (1998) edited book on Goethe's Way of Science where authors reprise Goethe's scientific work on "plants, colour, clouds, weather, and geography” (preface, xi) where Goethe combines "his intuitive awareness of art with the rigorous observation and thinking of science" (xi). Brady (1998) describes Goethe's study of plants and highlights the difference between a real plant drooping from need of water and the plastic plant showing its bright colors and bright green leaves no matter what. The plastic plant gives an illusion of life only because it has been designed to imitate living forms and then only at a distance. Humans can bring back the sense of life to the plastic plant by our own intentional effort, deliberately ignoring all details that do not fit the whole we are intending. But, the end result is a form of distortion that demands constant effort (Brady, 1998). These tenets of Goethe's science made me think about the simulation doll in terms of the plastic plant. The students must make the effort to overcome the inert doll with its activation controlled outside the room, a shift in cognition, in perception, in order to participate in the simulation activity. In summary, in the nursing simulation, it seems that the students get going forward in the simulation through responding to each other, but now we see as well, they are fighting to overcome a constant distortion; that of seeing the not-real doll as real.

\section{Later on in the Clinical Practicum...}

I arrived just shortly after a cardiac arrest and one of these students ran up to me and said, "Brenda it was terrible, their skin and chest felt nothing like the doll or the CPR dolls. I could not gauge my compressions, the depth, and I was so frightened. But he lived Brenda!”

A second student in the same simulation group I was visiting at a rural Emergency Department where she was undertaking her r practicum said, "Wow I just helped with cardiac arrest, it was so exciting!” Did the person live I asked? "No, she said without a trace of regret, remorse; it was so cool though." "Tell me about the person” I said. She described a young man almost her age who had died by his own hand. As she tried hard to shift back to this untimely death at a young age, she had trouble separating the life from the skill she had learned in simulation.

I (Brenda) thought to myself, at this point she has not seen the forming, the dynamic living form of the skill coming to fruition for this particular person and his life, his fragility; but, rather, her mastering of a skill. While this happens sometimes, the excitement over doing a difficult skill, it is not common with students participating in cardiac arrest (although I know of one other case 
where this happened later on). While the objectives for this simulation were for the students to 1) hone their skills before they do this on a human being, 2) to learn in a fairly controlled environment a complex skill, and 3) to practice new ways of integrating several shifting patient circumstances into a rapidly changing situation, what did these two students also learn in this simulation activity? They did not only learn what we expected them to learn. This simulation followed quite quickly by real life nursing experiences, shows perhaps on the one hand, good planning by the pedagogues of learning experiences encompassing new ways of being a nurse. But, on the other hand, there is unanticipated fallout from this experience; somehow, one student lost the sense of the person in the young man and the other student was horrified at the feel of the real human body in extremis. Others might say, 'Well the preparation and debriefing were not adequate; we have more life-like dolls now. It is so cost-effective, we protected the public, all went as expected in this scenario; the students performed!” But, both Susan and I have lingering and in fact, haunting wonders here, whether we have gone too quickly into simulation with its assured outcomes of giving experience in this particular health care professional technology without proper thought to other additional sequelae that might go along with the experience of simulation. While there is no shortage of literature promoting the inclusion of simulation in healthcare education, there are other authors raising questions about the evidence base for extensive adoption of these expensive technologies. Teteris, Fraser, Wright and McLaughlin (2012) point to the paucity of evidence to show that simulation actually improves patient outcomes. They note that much of the evaluation research about simulation shows increased student satisfaction and improvement of skills on the simulator. They conclude:

Simulators are too expensive to be simply adopted without good evidence of their utility. In clinical practice, before endorsing new treatments we must demonstrate that they are more effective than existing, less expensive treatments. Shouldn't we have the same approach to simulation training? (Teteris, et al 2012, p.142)

Parker and Myrick (2012) shed light on the experience of the students' participating in simulation activities. They describe the outcomes of patient simulation activities in nursing education through a grounded theory research approach. They identified the basic social process the students used to solve the basic social problem of facing simulation in high-fidelity dolls as "empowering through fading support" (p. 367). Fading support is described as "gradual withdrawal of support or assistance as the students move from the beginning phase (where others regulate their learning) to the final phase of self-regulation” (Parker \& Myrick 2012, citing Hadwin et al, 2005, p. 368). The substantive categories speak strongly to the experience of the students above; performing in a fishbowl (p. 368), suspending disbelief in the doll as a person (p. 369), and preferring to work on skills in a collaborative way with a tutor rather than a simulated doll, correspond to the anecdote above. Students, in their study, did not really see the students in the back room as supportive-but, rather, as more of threatening observers. They felt they were adrift in a fishbowl; they preferred the tutor being with them collaborating on complex skills rather than the simulation. The authors call for more research to build a body of knowledge in this field.

Returning to the anecdote, it is clear that the students probably do not see the doll as a real person but respond to each other to accomplish what needs to happen in their response to the changing simulation. Responding to each other assists them in getting through the simulated situation. It would seem, as educators, we did not anticipate enough the sequelae that might 
happen, distracted by the huge hegemonic safety, risk, and economic discourses impinging on the health professions at this moment (Seibold, Licqurish, Rolls, Hopkins, 2010).

Drawing on other literature to think through entwining self-body-other Akrich and Latour (1992) discuss technology using actor network theory and give us a purchase perhaps on understanding how the students began working together. These authors describe a shifting system of relationships where there are stages of milling around, one person starting to direct more than others, one person getting into the role more quickly, or persons taking time to choose what prescribed role they should take until the prescribed task is accomplished. What the authors describe here is also what happened with the nursing students in their nursing simulation. However, there is more happening than meets the eye.

In simulations, there are a number of exact things that must be done or completed and mostly, figured out experientially. Basically, the students have to determine in the moment what text is prescribed for the scenario as it happens, having prepared earlier for a rapidly changing situation of cardiac arrest. The operator who enacts the prescribed text with the doll also practices the art of simulation through manipulating the doll as the action proceeds. The doll ascribes a certain text to the students "take care of me now even though I look like a corpse, see me as a human being." The students, in the beginning, while they are shifting around experience a tension between the world prescribed by the text of the simulation along with what text the operator decides to enact knowing the capabilities of the doll. The students find the real world displaced somewhat, in order to take on these scripts, prescribed and ascribed. They experience the doll at a distance, but soon realize that the doll is compelling them to do certain actions and they better move along; the technology here is ever shaping the decisions they make, ever coaxing them onward. The learner has to overcome the contrived world of the doll, accept it, and just get on with it. Contrast this with Susan's description of students using their own body parts in terms of how they must move out of the object-ness of the situation to their subjectivity and professional selves.

\section{Student Fear}

Consider the skill of venipuncture - this can be for taking blood samples or for starting an intravenous line. While this becomes an "everyday" procedure for the practicing midwife, many students find this particular skill to be an enormous challenge.

SARA: I dreaded this - I am so afraid of needles. I feel cold sweat in my ears and hot sweat on my face. I want to throw up. Today I just watched - some of my friends were as nervous as me - their faces were green or white and they could not stand up. I watched one friend try to put the needle in the arm and it did not puncture the skin. She dropped it on the floor, then picked it up and tried again. I had to look away. Another friend got the needle in the first time but when I saw the blood rolling into the vacuum tube, I became light headed and had to lie on the floor.

Sara's venipuncture lab was not with a human volunteer; it was with a simulated arm. The blood is red dyed water. There is no pulsing, no pain. The arm can be punctured over and over. The idea is to provide a safe environment where students can master the mechanics of the procedures before needing to use these in real-world practice with real human clients. 
Sara furthered this point: “Do I see the 'arm' as human? No, not at all. I think that this is all about my fear of needles. I don't even really like touching the equipment. I know I will have to just get over this, but it is not going to happen today."

Bowyer, Pimentel, Fellows, Scofield, Ackerman, Horne, Liu, Schwartz, and Scerbo (2005) compared various IV practice simulators for effectiveness with medical students and found that the Laerdal simulator had the highest performance improvement. It is interesting that this simulator is not an "arm" - rather, it is a port (haptic vi device) where the student enters and manipulates the needle while watching feedback on a computer screen. In a way, this is a simulation least like real life. Perhaps it is most like video gaming technology.

SUSAN: Two days later, I watch from a corner of the room - Sara is being encouraged by her friends to "try." Does she try on a sponge or the rubber arm? No - one of her friends has "volunteered" to be Sara's first puncture. Groups of six gather round. Sara is white but she is holding the needle. One of her friends is rubbing her shoulders and another is encouraging her to breathe deeply. The one whose arm is now turning blue from having the tourniquet on for so long is talking about the movie she saw on the weekend. Sara looks at her and asks hesitantly "now?" and she nods. All heads huddle around and I can no longer see the details but suddenly there is a cheer and many words of congratulations - "you got blood Sara!” One friend quickly passes Sara a glass of juice and pushes her into a chair. When Sara leaves the classroom a few minutes later, you can see that her legs are still a bit wobbly, but she is wearing a HUGE smile.

While this learning was initiated by the need to develop competence in a very particular skill necessary to the safe practice on midwifery, I (Susan) should revisit Bildung (Bohlin, 2008) here and reflect how the group moved into their being as novice midwifery students. They recognized Sara's needs and fears and shifted from a simply technical task to a moral responsibility for themselves as a collective - a women with women commitment, a melding of their selvesbodies-worlds in ways far more important to their future careers than simply the task of putting a needle in a vein.

In a way, the students perceived the logic of the practice here. The goal was to learn to start the IV however the one student could not over the horror of the fake plastic arm. She then started one on a live human being and it is somehow a better learning experience.

\section{Cyborg Student}

Another version of happens when the student becomes one with the manikin. The student cannot give birth and the simulator cannot without human manipulation. The midwifery student learns techniques and support; the student who is birthing learns the mechanisms of the birth process because she must direct the baby through the torso.

What is the student's experience of body-self-world when recreating her world to include an object body part (the torso and baby), a life situation that is not, in reality, part of her contemporary world (pregnancy, labor, birth) and a role that may not be part of her past, present 
or future (the mother)? The student-woman/client "pushes” the baby through the torso. Not with her uterus, not through her loins - but using her arms, touching the inside of the torso and the baby all made of a combination of hard plastic and nylon cloth. Certainly this is an embodied experience. Most students comment on how physically taxing it is to push that baby out of the torso and how hard it must be to have to push for hours when our simulated exercises generally only last for minutes. But, the student-woman/client body does not experience the pain of contractions, the stretching of her body needed to push out the baby, nor does she risk lacerations or hemorrhage.

Some students are very good at this birthing role-play - others clown around a lot. Is this like gallows humor? Use to ease tensions when there is a lack of ease in facing the realities of a particular situation? The "I will be taking on this responsibility very soon" anxiety?

\section{Returning to Bildung}

We return to Bildung here. While it is now understood as formation or development, there is an older form of Bildung that is a natural shaping. The earlier understanding was to portray form, to see Bildung in the context of becoming with the overall notion of movement according to writings from Goethe (Bradly, 1998). The plastic plants Goethe refers to (Bradly, 1998) might just compare to a cyborg student learner. While the nursing student could have been unable to locate the heartbeat on a live patient, the heart beat of the simulation model is impossible to miss. The midwifery student has to physically use her body on this midwifery model. Is this not better for the actual shifting back to the real lived world?

Perhaps the midwifery students' hilarity is to say, "We know this is not a real mother delivering but it is not a plastic plant either; it signifies something to us." For nursing students, at first the doll signifies an inanimate doll similar to a corpse, then as either the students or the operator try to ascribe the life text to the doll, a shift happens and the students begin to participate. The corpse has little potential to be otherwise. It is an aspect of this doll's condition resulting in a loss of potency in the world. This inorganic doll requires a form of cognition quite different from that of the organic. So perhaps the underlying educative process here is not learning at all or being 'trained' but, actually, the students having to make cognitive shifts to accommodate the learning strategy of role-playing along with supporting each other.

\section{Virtual Student}

The project that stimulated my (Susan) interest in this topic for the paper is a collection of virtual case studies for health care students and professionals. These case studies are integrated into the midwifery curriculum, particularly in the third year where students are learning about "care management." Similar to the 'Choose Your Own Adventure' books for children, these virtual case studies invite the student to work through a case making decisions along the way. Students can deliberately or unintentionally venture into errors and use of poor judgment and then learn the consequences of their actions. Does the student take these lessons to heart? On one hand, the student may feel let down/disappointment - maybe even fear, anxiety - dropping out of one's stomach - "the baby died, do you want to start again?" The blood-loss is increasing, when will it be too much? Or is it too much like the games where one can annihilate the world then turn off 
the console and go eat dinner? It is all clean and neat - no blood, no mess, no cries or screams like Norm Friesen's (2011) description of the cyber dissection of a frog - much more appealing than the frog that started off live on your lab bench.

When we look at self-body-world in virtual learning, we need to ask if there is a body in cyberspace? Many concentrate on space/world in cyberspace, emphasizing the humantechnology relationship. Others, like Lars Løvlie (2005) suggest that our question about embodiment ought not to be one of is, but rather one of how, drawing us back to the notions of dwelling and place.

We worry that the use of patient mannequins does not bring into play the full range of human interaction in human encounters, such as nonverbal cues or psychological withdrawal. The experience is less realistic, less ambiguous than real clinical situations. Perhaps Brenda as an actor encouraged the students to break out of their "what should I do now with this lump of plastic?” and act.

\section{Bringing the ideas together}

As we continue to ponder the questions related to the student experience of simulation, we turn again to Gadamer (1992). He might say that the students learned how to play the game that is prescribed and the response needed to be tailored to the text ascribed to the doll. Gadamer uses the idea of play or game as a way to experience truth. In the true nature of play of a true game or real professional situation, the player loses herself in the play; it cannot be seen as an object now or only a game. The mode of being of the play is not to be understood as something a person does. Rather, the primacy of play over the consciousness of the player is fundamental. And, soon the to and fro motion of play moves, has motion AND the player plays the rules of the game without immediate consciousness of them, the player sees multiple possibilities out there in the game but also within a field where movement is allowed to take place.

Perhaps this is the question with simulation and its rules, and texts of tasks. Are students prevented from actually moving themselves beyond the rules of the prescribed game? They are not able to get beyond the rules of the simulation so as to lose themselves in the sheer wonder of playing the game without consciously, constantly thinking of the rules. When one moves more fully into the game, to acting as a professional, understanding in a to and fro movement, act, treat, assess, act, treat in a specific context. The player still decides one way or the other on this possibility or another; for if she does not, there is no overcoming of self in the real moment and into a more object like existence for a moment; and like the doll, the simulation, all remains static.

Rather than we as educators ascribing too much to what the doll, learners and students can do, perhaps it is rather, to be cautious, to note limitations of the doll at the beginning, to note things the doll can do. BUT at the same time, take the time in debriefing (Fanning \& Gaba, 2007). Not just of the actions of the students but of an existential discussion on those things now seemingly in simulation left in the wind for the students to bridge the gap between simulation and life practice-some will see it, others won't. Santos Salas \& Cameron (2010) and Cameron \& Santos Salas (2009) show how the actual world that nurses encounter on a home visit, holds mostly unprescripted care; something bursts into view in that world that must be faced and dealt with immediately.

Benner (2010) writes about salience, understanding what is going on in the health care situation and getting prepared to act, clinical reasoning described as: 
nurses' deep background knowledge: understanding of the nature of the particular situation bound as it is by time and context...because this understanding is based on experiential learning, in a clinical situation the educators will often ask questions in advance to help the student ferret out what must be attended to on a particular day. Especially if the situation is too novel for the student, the teaching will have to frame the situation explicitly. It is highly risky to allow the student to discover too late, for example, that he or she should be attending to lung sounds looking for early pulmonary edema” rather than focusing on something else. (p. 116-7)

Benner (2010) corresponds to Parker and Myrick's (2012) findings that the students prefer to do these complex skills in collaboration with an instructor, not in a simulation activity. Why might this be?

It might be useful to examine thoughts of human/technology interface. Bruno Latour (1987) writes that in the interface between humans and nonhuman objects most likely there is a script or text written somewhere that contains prescribed behavior. There is also an inanimate object with which we must interact. He uses an example of a door and instructions for closing a door. No one who enters this door closes it despite the instructions. Latour (1987) writes that we are often in situations where technology tells us what to do, such as the instructions for replacing toner in the printer: he adds ironically that the machine does not say add yourself to this process! (Letour, 1987)). Yet, that is precisely what must be discerned.

Heidegger (1977) moves toward the four causas that philosophy has used for the making of something to enhance life, of how the craftsperson brings some technology into view. He writes of the making of a silver chalice. Causa materialis is the material used; causa formalis is the form, causa finalis the eidos, the sacrificial rite in relation to the chalice's use in society, and finally the causa efficenens of where the chalice is used by humans to enhance human life.

Certainly the causa materialis could be the doll and the plastic material the doll is made of or it could be the nursing actions that are involved in lifesaving actions. But, it could also be the students, the making of health professionals, midwifery and nursing. For Susan, and midwifery, the simpler model of the pelvis allowed for the student learners to take it for what it was, a crude yet life model of a woman's pelvis. Then, they could activate it through combining, theoretical knowledge, and previous practice knowledge; a much more simple technology, the students using simple models and themselves.

The causa formalis could be the need for the nursing students to act in a rapidly changing health status of this doll or it could be just getting acclimatized to the doll itself. It is intended for the nursing students to move into life saving actions but does it really work this way? The causa finalis is the need for the student to be prepared when this happens in nursing practice or is it just simply the need to perform in this moment as a way to convince the educator they have done the best preparation; skills practiced without the inherent meaning? Or, is it mainly the need in the world for this life saving activity, the assistance in birthing? The causa efficenens is a bit questionable at this time. How does the simulation enhance human life given the reactions of the two students in real life practice? Does it truly assist them to think and care?

Schiavenato (2008) states that the need for safety in patient care depends on the competence of the medical practitioners with certain skills. But in nursing education, it is not clear in terms of a consistent theoretical perspective guiding simulation in nursing other than with diminishing resources; an expenditure of money on a high-fidelity doll might seem 
expedient to learning skills. Schiavenato (2008) voices concerns about proper applications of tools, beyond a single product or technology, "lest that product or technology become the concept itself" (p. 391) and not the making of a midwife and nurse. Heidegger (1977), in his essay on the Question of Technology, advises caution with the use of any technology to prevent human beings from being "ordered" or activated by the technology. Here we might talk of mastery (Heidegger's word) meaning that the technology contains the ability to take mastery over us unless we are very wide-awake. He talks about developing a free and right relationship with technology that only comes with understanding the essence of it.

What really is the logic of care here? Annemarie Mol (2008) writes about the logic of care, with logic as a philosophical word she uses not to mean discourse, but rather to signify what is the "rationality... of the practices I am studying" (p. 8). The contrast with discourse Mol makes plain:

My concern is not with the ways in which socio-material orderings come into being and establish themselves, nor with the power involved in that process...It invites the exploration of what it is appropriate or logical to do in some site or situation, and what is not. It seeks a local, fragile and yet pertinent coherence. This coherence is not necessarily obvious to the people involved. It need not even be verbally available to them. It may be implicit; embedded in practices, buildings, habits and machines. And yet, if we want to talk about it, we need to translate a logic into language. (p. 8)

For Susan and Brenda, we could ask what is the logic of care (Mol, 2008) underpinning the use of simulation? For us, it would be to ask what is the logic of practice or logic of learning that is going on here? Is it something overt or something hidden? Are we, in fact, not encouraging student learning in any way? Are we, in fact, doing a form of pedagogical violence to the learners, making them shift from contrived worlds to lived world where we attempt to simulate the human being? Heitler (1998) discussing Goethean Science, states, "a world conceived without the human being is no longer a whole and healthy world in which people can live” (p. 66). It seems a reduction of the learner, yet as a practice we know we are mandated to consistently offer new ways to take on a practice. Is it like putting something inside the student's head from the tutor's head as lecture is described? Is it an attempt to put embodied skills inside the learner or is it mainly a means to an end, cheaper, efficient perhaps, but has nothing to do with the development of a professional person?

\section{To Conclude}

We propose that we need more work in identifying what is going on in simulated learning rather than embracing new technologies without question. The authors know that there is a proliferation of literature regarding simulation in nursing, medicine (Anders Ericsson, 2004). Midwifery (James, 2011), and other disciplines all call for in-depth design for simulation activities and careful planning of the design of the activity (Deker, Sportman, \& Puetz, 2008). We do not intend to denigrate their work, as it has been most helpful. But, it is important to reconsider the entwining oneself as learner with technology learning...embodied to disembodied interface...play acting a midwife to inanimate body trying to make it like a real body/live plant 
through philosophical inquiry The authors believe we need continued study in these philosophical areas of self-body-other and plan to continue this inquiry.

- Realize the effort of the learner to enter the simulation world; cognitive plus bodily shifts as object student relating to objective simulation; but unable to do this entirely due to all the extraneous watchers/observers.

- Realize they may not learn the ascribed text of the doll but the text of something else (e.g. student fear of the simulator not the actual undertaking of the IV)

- Realize until we understand more fully the world of practices and how health care professionals engage in the process of understanding what is going on, we cannot pick and choose technologies to augment skill acquisition; critical analysis of simulation activities must be undertaken RATHER than adopting what is becoming a dominant discourse health care curriculum design.

- Don't limit the possibilities in the real world text through what is prescribed/texted in simulation; much more preparation for the simulation activity and debriefing needed (Benner, 2010).

- Don't believe that the students have picked up a skill or capacity right away. Ask them what they have learned AFTER the prescribed text is put away. Search for how this experience is being integrated into their overall learning of health care situations - in a way, a broadening of the script.

- Document experiences in clinical practice from the student and clinical instructor/tutor point of view to build up a body of knowledge in this philosophical area.

Simulation models are not new, but the proliferation of high fidelity models is relatively new in health professional training. The pressure to use these devices is driven by risk managers and the industry that obviously benefits from the initial purchases and the necessary replacements and upgrades. Much of the simulation literature provides a non-critical support of the use of such technology in the education of health professional students. Yet, now the technology has been used for some time, our challenge is to continue to explore the student experience of simulation in the lab with the object model "other" and how to best shift at the bedside to the subject person "other."

\section{References}

Akrich, M. \& Latour, B. (1992). A summary of a convenient vocabulary for the semiotics of human and nonhuman assemblies. In W. Bijker \& J. Law Shaping Technology/Building Society (pp. 259-264). Cambridge MA: MIT Press.

Benner, P., Sutphen, M., Leonard, V., Day, L. (2010). Educating nurses: A call for radical transformation. San Francisco: Jossey Bass.

Bohlin, H. (2008). Bildung and moral self-cultivation in higher education. What does it mean and how can it be achieved? Forum on Public Policy: A Journal of the Oxford Round Table. http://forumonpublicpolicy.com/summer08papers/curriculumsum08.html

Bowyer, M.W., Pimentel, E.A., Fellows, J.B., Scofield, R.L., Ackerman, V.L., Horne, P.E., Liu A.V., Schwartz, G.R.\& Scerbo, M.W. (2005). Teaching intravenous cannulation to medical 
students: Comparative analysis of two simulators and two traditional educational approaches. Studies in Health Technology and Informatics. 111: 57-63.

Brady, R.H. (1998). The idea in nature: Rereading Goethe’s organics. In D. Seamon \& A. Zajonc. (Eds). Goethe's way of science. A phenomenology of nature. (pp. 83-114). New York: State University of New York Press.

Cameron, B.L., Santos Salas, A. (2009). Understanding the provision of palliative care in the context of primary health care: qualitative research findings from a pilot study in a community setting in Chile. Journal of Palliative Care; 25(4):275-83.

Deker, S., Sportman, S., \& Puetz, L. (2008) The evolution of simulation and its contribution to competency. Journal of Nursing Education, 39(2), 74-78.

Ericsson, K. A. (2004). Deliberate practice and acquisition and maintenance of expert performance in medicine and related domains. Academic Medicine, 79(10), S70 -S81.

Fanning, R.M. \& Gaba, D.M. (2007) The role of debriefing in simulation-based learning. Simulation in Healthcare, 2(2) 115-125.

Friesen, N. (2011). Real vs. virtual dissections: Brilliance and transparency or encumbrance and disruption? Environmental and Architectural Phenomenology, 22(2), 6-10.

Fox, S.D., \& Damazo, R. (2013). Using simulation to teach nurses. In C.J. Huston, Professional Issues in Nursing: Challenges and Opportunities ( $3^{\text {rd }}$ ed.). (pp. 47-66). Baltimore: Lippincott, Williams and Wilkins.

Gadamer, H.G. (1992) Truth and method. New York: Crossroad Publishing Corporation.

Harder, N. (2010). Use of simulation in teaching and learning in health sciences: A systematic review. Journal of Nursing Education, 49(1), 23-28.

Heitler, W. (1998). Goethean Science. In D. Seamon \& A. Zajonc (Eds). Goethe's way of Science. A Phenomenology of Nature. (pp. 55-70). New York: State University of New York Press.

Heidegger, M. (1977). The question concerning technology. In W. Lovitt, The Question Concerning Technology and Other Essays. (pp. 3-35). New York: Harper Torchbooks.

James, S. (2011). Midwifery sims In R.H. Ellaway and D. Tops (Eds). Expanding simulation: Adventures in simulation-based health professional Education in Northern Ontario. (pp. 2427). Sudbury: Northern Ontario Medical School.

Langer, S.K. (1957). Problems of art. New York: Charles Scribner’s Sons. 
Latour, B. (1987) Science in action. How to follow scientists and engineers through society. Cambridge MA: Harvard University Press.

Løvlie, L. (2005). Is there any body in cyberspace? Or the idea of a cyberbildung. Utbildning \& Demokrati. 14: 115-130.

Mol, A. (2008) The logic of care: Health and the problem of patient choice. New York: Routledge.

Parker, B.C., \& Myrick, F. (2012). The pedagogical ebb and flow of human patient simulation: Empowering through a process of fading support. Journal of Nursing Education, 51(7), 365372.

Santos Salas, A. \& Cameron, BL. (2010). Ethical openings in palliative care practice. Nursing Ethics, 17(5), 655-65.

Schmitt M.H., Gilbert J.H.V., Brandt B.F., \& Weinstein R.S. (2013) The coming of age for interprofessional education and practice. The American Journal of Medicine, 126, 284288.

Schiavenato, M. (2009). Reevaluating simulation in nursing education: Beyond the human patient simulator. Journal of Nursing Education, 48(7), 388-394.

Seamon, D. ,\& Zajonc, A. (1998). Goethe's way of science. A phenomenology of nature. NewYork State University of New York Press.

Seibold, C., Licqurish, S., Rolls, C., \& Hopkins, F. (2010). 'Lending the space’: Midwives perceptions of birth space and clinical risk management. Midwifery, 26: 526-531.

Teteris, E., Fraser, K., Wright, B.,\& McLaughlin, K. (2012). Does training learners on simulators benefit real patients? Advances in Health Sciences Education. 17, 137-144.

\footnotetext{
${ }^{\mathrm{i}}$ We or us refer to the authors throughout the paper.

ii The stories come from the authors' previous research, presentations and teaching experiences.

iii Speculum examination - the use of a duck-billed instrument to examine the woman's cervix and vagina and to take sample for tests such as the Papanicolaou smear for the detection of cervical cancer.

${ }^{\text {iv }}$ Haptic technology uses a sense of touch to guide one through a particular action or technique. In the case of the haptic IV portal, the student inserts the IV needle into an opening in a box that then provides a series of pressures to the needle that mimics the sensations that one would experience while inserting the needle into a vein in the patient's arm. A computer monitor shows the progression of the needle into the vein.
} 
v An earlier version of this paper was presented at the 2011 International Human Science Research Conference where the theme of the conference was the intertwining of self-bodyworld.

vi Simulation includes three types documented in much of the literature: "low-fidelity simulation: task trainers, non-computerized; mid-fidelity simulation: standardized patients, computer programs, video games; and high-fidelity simulations: computerized human patient simulator manikins (Harder, 2010, p. 24). 